\title{
Integração sul-americana para defesa dos recursos naturais
}

\author{
Stephanie Albertini Daenekas \\ Camila Alves da Costa
}

RESUMO: Diante da necessidade de proteger os Recursos Naturais da América do Sul das ameaças externas causadas pela escassez em outras partes do mundo, o Conselho de Defesa Sul-americano se apresenta como equilíbrio entre as teorias idealista e realista, sugerindo a integração regional como estratégia de Defesa. Abre, assim, um espaço de diálogo para tratar conflitos internos, projetando uma nova identidade sul-americana independente e autônoma.

Palavras-chave: Defesa. América do Sul. Recursos naturais

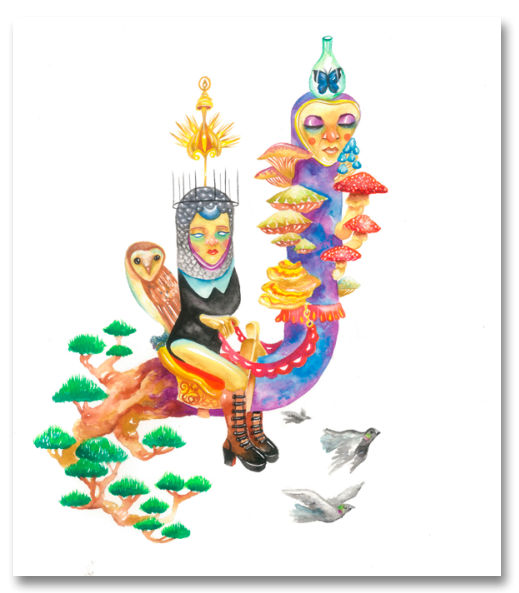

\section{South American integration for the defense of natural resources}

\section{Stephanie Albertini Daenekas}

Bacharel em Relações Internacionais pela Universidade Paulista (2017) e pesquisadora do Observatório das Nacionalidades. Linhas de pesquisa: Estudos Estratégicos, Defesa, América Latina. E-mail: sad. daenekas@gmail.com

\section{Camila Alves da Costa}

Mestra em Estudos Estratégicos da Defesa e Segurança Nacional pela Universidade Federal Fluminense (2011). Pesquisadora do Observatório das Nacionalidades e co-editora da revista Tensões Mundiais. E-mail: camila_al_costa@ yahoo.com.br

\begin{abstract}
Faced with the need to protect South America's Natural Resources from external threats caused by scarcity in other parts of the world, the South American Defense Council presents itself as a balance between idealist and realistic theories, suggesting regional integration as a strategy for Defense, opening a space for dialogue to deal with internal conflicts, and projecting a new independent and autonomous South American identity.
\end{abstract}

Keywords: Defense. South America. Natural resources

\author{
RECEBIDO: $14 / 03 / 2018$ \\ APROVADO: 02/05/2018
}




\section{INTRODUÇÃO}

O presente trabalho propõe um estudo sobre a evolução do Conselho de Defesa Sul-americano (CDS) como alternativa eficaz para a defesa dos recursos naturais da região, desde sua idealização, no contexto da União das Nações Sul-americanas (UNASUL), até a aplicação prática dos princípios de seu Estatuto de dezembro de 2008.

O CDS surgiu em um período de governos majoritariamente progressistas na América do Sul, os quais, mesmo com diferenças entre si, tinham como objetivo a proteção e a independência regional. Sem ter tido muito tempo para sua evolução, o CDS enfrenta hoje uma fase neoliberal na América do Sul que favorece a subordinação ao norte, deixando de lado o propósito integracionista da UNASUL - e seus frutos, como o CDS.

O CDS tem como objetivos avançar na construção de uma visão compartilhada em matéria de defesa e promover a troca de informações da situação regional, incentivando o diálogo com outros países da América Latina e do Caribe. O Conselho se compromete a adotar medidas de fomento e confiança, promovendo o intercâmbio na capacitação militar e cooperação acadêmica dos centros de estudo de Defesa. Em suma, o CDS se propõe a unificar os princípios de Defesa dos países membros e aplicá-los em conjunto, fortalecendo o papel da América do Sul frente às ameaças externas e começando pela não-intervenção de outros países nos assuntos internos.

Diante da falta de representatividade em assuntos estratégicos nas Organizações Internacionais existentes, em 2008 foi proposta, na UNASUL, a criação do CDS, através do qual os 12 países signatários (Argentina, Bolívia, Brasil, Chile, Colômbia, Equador, Guiana, Paraguai, Peru, Suriname, Uruguai e Venezuela) se comprometem a atuar conforme os princípios de soberania, não-intervenção e defesa da democracia e dos direitos humanos, além de fortalecer o diálogo para a resolução pacífica de controvérsias, promover a cultura de paz em um ambiente livre de armas nucleares, atuar em cooperação para reduzir as assimetrias regionais e trabalhar em conjunto para a defesa da soberania de seus recursos naturais. 
O Estatuto do CDS é regido pelos mesmos princípios e propósitos estabelecidos na Carta das Nações Unidas e na OEA, mas, na prática, ele propõe a construção de uma identidade sul-americana que leve em conta as características específicas da região e fortaleça a cooperação com a América Latina e o Caribe.

Através do estabelecimento de uma região pacífica, mas com uma identidade de defesa ativa através do CDS, a América do Sul colocar-se-ia em um grau superior de autonomia ao desenvolver as indústrias nacionais de Defesa, e, principalmente, de estudos estratégicos, compartilhando o treinamento e o aperfeiçoamento das equipes em todos os níveis. Conforme apontado por Manuel Domingos Neto (2016), cabe ao Estado se preparar para a guerra. Quando isso não ocorre, sua existência passa a depender de potência estrangeira, o que compromete sua autonomia.

Embora a América do Sul tenha o histórico de ser uma região pacífica, existem muitos pontos na relação entre Estados que merecem atenção quanto à Defesa. Neste sentido, o CDS também tem um papel importante na proteção dos recursos naturais, que representam razões mais do que suficientes para que a América do Sul se articule na promoção de uma estrutura de Defesa soberana, através de uma perspectiva de cooperação que permita aos países um nível de controle mais complexo.

Foram considerados para essa pesquisa os principais recursos naturais, como as reservas de Mata Atlântica, o petróleo venezuelano, o pré-sal brasileiro e o Aquífero Guarani, todos afetados pela fragilidade da região com o histórico de exploração da Europa e, depois, dos Estados Unidos, devido à riqueza local de recursos já escassos em outras partes do mundo. (BANDEIRA, 2003)

Assim como a descoberta do pré-sal fez despertar o cerco da IV frota estadunidense no litoral brasileiro, o contínuo crescimento demográfico mundial, aliado a péssimos hábitos de consumo, também coloca em risco as bacias hidrográficas sul-americanas grandes reservas naturais de água potável, cobiçadas por potentes conglomerados industriais.

O Departamento de Defesa de cada país, individualmente, não tem o alcance necessário para proteger efetivamente esses recursos, principalmente porque muitos deles são compartilhados por 
países distintos, como a floresta amazônica e o Aquífero Guarani. Dada a importância dos recursos naturais e as ameaças surgidas recentemente (como a instalação de bases estadunidenses na Colômbia e a movimentação da IV frota no litoral brasileiro), o tema é de extrema urgência e deveria ser prioridade para os governos da região, independentemente de orientação política ou inclinação ideológica. Afinal, o alinhamento comercial e econômico com os EUA, a China ou qualquer outra potência global não deveria interferir na autonomia da região ou na soberania dos países sobre seus recursos.

Mesmo os países mais proeminentes da região apresentam deficiências no campo da Defesa, as quais podem ser compensadas por meio do CDS. Desenvolvimento tecnológico, armamentos e treinamentos de pessoal podem se complementar em um ciclo funcional de cooperação. Para que ocorra essa integração em Defesa, o CDS precisa ter condições de estabelecer internamente uma relação de confiança mútua, que não arrisque ferir a soberania de cada país membro. Uma vez construída essa relação, o CDS pode possibilitar à América do Sul ter independência para tratar as questões de Defesa e apresentar-se no contexto internacional como um bloco forte e autônomo.

Diferenças ideológicas na região são, também, um importante ponto na formação do Conselho. Mas a tendência política de cada governo deveria ser refletida nas deliberações do grupo, e não justificar o abandono do CDS como instrumento de integração. O objeto de preocupação da Defesa Nacional deve estar acima das posturas políticas, e o CDS tem o papel de desenhar um projeto de Defesa supranacional contínuo.

\section{A INTEGRAÇÃO REGIONAL COMO INSTRUMENTO DE DEFESA}

Ao longo da história, blocos e associações com fins de integração comercial e econômica foram criados, e os temas de desenvolvimento social e infraestrutura começam a ser trabalhados de forma conjunta entre Estados que têm objetivos em comum. Apesar disso, os Assuntos Estratégicos ainda são um tema sensível, 
e qualquer associação que procure unir países em seus objetivos de Defesa, onde haja troca de tecnologia e acordos de lealdade, é vista com olhos de desconfiança pela comunidade internacional.

O estudo das Relações Internacionais procura entender os acontecimentos na história para prever a tendência do futuro, e faz isso através das teorias de Relações Internacionais. A teoria liberal entende que a paz somente pode ser alcançada por meio de um sistema livre e cooperativo, onde a liberdade do indivíduo o leva a buscar o melhor para si, e, como consequência, tende a gerar uma sociedade internacional interdependente, que não tem interesse na guerra ou justificativa para ela. Baseada nas ideias de Rousseau, Kant, Hegel, e outros teóricos idealistas, sugere a organização do sistema internacional, criando uma comunidade de nações regulada por normas internacionais que refletem os princípios do indivíduo.

A corrente idealista parte do princípio de que o homem é bom, procura a paz, e que dessa paz advém prosperidade às nações. (NOGUEIRA; MESSARI, 2005)

O idealismo expresso na obra "A Paz Perpétua", de Immanuel Kant, propõe um mundo onde a cooperação mútua geraria prosperidade e interdependência, o que tornaria a guerra um meio contraditório de expansão, já que o sucesso de um Estado estaria diretamente relacionado à paz do seu entorno.

Em "O contrato social", Rousseau (2006, p. 16) trata da interdependência entre indivíduo e sociedade, afirmando que "o dever e o interesse obrigam igualmente as duas partes contratantes a se auxiliarem de forma recíproca". Tal assertiva pode também ser aplicada, em maior escala, à interdependência entre Estados que formam a comunidade internacional. A partir desse entendimento de que o homem tende a buscar seu desenvolvimento e, por consequência, alcançar o crescimento do grupo, o idealismo se apoia nos princípios do liberalismo econômico: a sociedade bem ordenada se autorregula, e corrige, através das instituições e processos, quaisquer desequilíbrios e ineficiências (NOGUEIRA; MESSARI, 2005). Encontramos sentido nessa afirmação se avaliarmos que o comércio, originalmente uma troca, sobrevive e se desenvolve na medida da capacidade de seu mercado. Países que 
têm negócios entre si perdem muito de seu próprio potencial de lucro quando há controvérsias entre as partes. Essa relação de dependência diminuiria o risco de guerras e aumentaria a flexibilidade em buscar a compreensão das diferenças entre culturas, linguagens e diferenças geopolíticas. Portanto, é possível afirmar que, mesmo com o propósito econômico, e não por princípios pacificadores, as relações comerciais entre Estados são um forte elemento na promoção da paz e facilitação da cooperação.

A teoria realista, por outro lado, trata do poder como objetivo. Ao invés de um ambiente de cooperação, o realismo identifica o sistema internacional como um aglomerado de Estados com interesses próprios que devem, acima de tudo, manter sua soberania, garantindo sua própria defesa e desconfiando de todos.

Para os realistas, o Sistema Internacional anárquico não favorece a cooperação entre os Estados, por não haver um ator supranacional com poder de organizar as relações internacionais. O realismo valoriza a soberania do Estado e legitima o uso de força para fins de defesa, acima do princípio da cooperação. A vantagem desse ponto de vista é que cada Estado tem a liberdade de definir sua própria política doméstica e seus interesses regionais, e exercer sua soberania da forma como entender mais eficiente, independentemente de seus vizinhos ou eventuais adversários. Por essa lógica, o Estado desenvolve sua política externa com foco no poder, e mede esse poder se comparando a outros Estados. Nesse cenário, há grande investimento no arsenal e treinamento militares, pois, em meio a negociações comerciais, econômicas e assinaturas de acordos e tratados diplomáticos, a sombra da guerra possível estará sempre assegurando o status quo, garantindo que a superpotência militar seja também a superpotência econômica e política, regional ou global.

Enquanto o idealismo imagina como o mundo deveria ser, o realismo aponta a realidade do mundo como é. Idealizar um sistema internacional perfeito não traz a real dimensão dos problemas a serem tratados até que se alcance a paz e a estabilidade. Ao mesmo tempo, enxergar o mundo com olhos realistas, que não veem um futuro diferente, não permite a evolução transformadora das relações. Conforme Edward Carr (2001), as duas teorias não 
são excludentes, mas complementares. O idealismo difundido no período imediatamente posterior à Primeira Guerra mascarava a realidade do momento e poderia levar à volta da diplomacia secreta que motivou o conflito; por outro lado, o realismo, por si só, acabaria com todas as esperanças de uma convivência pacífica entre os Estados e impediria o desenvolvimento de novos modelos de diplomacia e dissuasão.

Diante da necessidade do equilíbrio entre as teorias realista e liberal no planejamento da Defesa de Estado, a integração regional se apresenta como opção a ser discutida.

Quando se fala em cooperação com fins de Defesa, o primeiro fator a se considerar é o Dilema da Segurança: quando um Estado se arma para sua própria segurança, o outro entende isso como uma ameaça em potencial e se arma também, com o objetivo de se tornar páreo em relação ao primeiro. Sucessivamente, os países tendem a se armar cada vez mais, como em uma competição de demonstração de poder - o que se viu exemplificado durante a Guerra Fria. Há, porém, uma diferença marcante entre a cooperação nas balanças de poder regional e global. Uma configuração multipolar equilibrada pode incentivar a cooperação em defesa, para conter um candidato a hegêmona regional, enquanto a troca de informações possibilitaria a identificação de emergências revisionistas. Na possibilidade de um Estado concentrar sobremaneira os ganhos da cooperação, a formação de uma aliança para a reestabilização do sistema forçaria o equilíbrio das relações novamente. A capacidade de autogerenciamento das relações de poder dentro de um bloco de Defesa fortalece a identidade regional na medida em que a troca de experiências e recursos equilibra o nível de conhecimento para desenvolvimento de novas estratégias. (REZENDE, 2015).

O órgão superior responsável pela normatização e fiscalização dos assuntos relacionados à paz e à segurança internacionais é o Conselho de Segurança das Nações Unidas (CSNU), em vigor desde 1945, e composto por cinco membros permanentes e dez membros não permanentes com cadeira rotativa a cada dois anos. ${ }^{1}$

1 EUA, Rússia, França, Reino Unido e China. 
A formação desequilibrada do CSNU, que exclui a América Latina e o continente africano, reflete a desigualdade das decisões tomadas por essa instituição, uma vez que seus membros permanentes são Estados já estabilizados economicamente e com reconhecido poderio militar, além de muitos interesses ocultos em conflitos ao redor do mundo. Portanto, as questões levadas ao Conselho serão sempre tratadas de forma parcial e assimétrica. Existe um grupo de países - entre eles o Brasil - defensores de uma reforma no CSNU que permita um olhar mais justo e democrático sobre as questões de Segurança global.

Também no período pós Segunda Guerra foi criada a Organização do Tratado do Atlântico Norte (OTAN), constituída por países da Europa e da América do Norte com o compromisso de defenderem uns aos outros. Sua formação foi um sinalizador para a extinta União Soviética de que qualquer ameaça a um dos países membros seria entendida como um ataque ao grupo. Encerrada a Guerra Fria, a OTAN permanece atuando como elemento integrador da segurança desses Estados, tendo inclusive importante participação na invasão pelos Estados Unidos ao Afeganistão em 2001, sob o pretexto de combate ao terrorismo (COSTA, 2007).

Nas Américas, a Organização dos Estados Americanos (OEA) é o mais antigo acordo regional. Criado em 1890 como a União Internacional das Repúblicas Americanas, tem o objetivo de garantir a democracia, os direitos humanos, a segurança e o desenvolvimento da região, através de diálogo político, cooperação e instrumentos jurídicos. No campo da segurança, a OEA tem uma função mais reativa: intervir em situações de controvérsias entre países membros. Não busca, entretanto, desenvolver uma política específica de integração e desenvolvimento exclusivamente de defesa regional - além de estar, assim como o CSNU, fortemente sujeita à influência da superpotência norte-americana, que delibera de acordo com seus interesses próprios.

Outro efeito da Segunda Guerra na área da integração para a Defesa foi o Tratado Interamericano de Assistência Recíproca (TIAR), um mecanismo de defesa coletiva formalizado em uma aliança militar entre os Estados Unidos e os países latino-americanos. Em 1945, não cabia falar em estruturar as Forças Armadas na América 
Latina; a intenção do Tratado era que os EUA firmassem seu domínio e influência na região, o que, para o subcontinente, representava ter como guardião o Estado que viria a se consolidar como potência militar. A princípio, o TIAR não previa a formação de exércitos conjuntos, troca de tecnologia ou compartilhamento de estratégias. Servia apenas como uma aliança de defesa comum, caso qualquer Estado Americano fosse objeto de agressão, armada ou não. No auge da Guerra Fria, em 1962, com a saída de Cuba da OEA e difusão da Doutrina da Segurança Nacional (DSN), enfatizava-se o alinhamento ideológico e doutrinário dos setores militares latino-americanos aos EUA. Em 1982, na Guerra das Malvinas, o apoio dos EUA ao Reino Unido contra a Argentina deixou clara a obsolescência do TIAR, que, devido à falta de interesse na atualização de seus termos, foi abandonado como mecanismo regional (ABDUL-HAK, 2013).

Um exemplo importante de cooperação, que atingiu nível de confiança suficiente para o compartilhamento de estratégias, é da União Europeia (UE), formada hoje por 28 países. Surgida da iniciativa de alguns desses países (Alemanha, Bélgica, França, Itália, Luxemburgo e Países Baixos) após a Segunda Guerra, consistiu na formalização e aprofundamento das relações entre eles, de forma que a dependência econômica reduzisse o risco de conflitos na região. A partir da integração comercial, o grupo desenvolveu um mercado único, com livre circulação de pessoas, e se propôs a trabalhar conjuntamente pela defesa dos Direitos Humanos, da Igualdade e do Meio-Ambiente, entre outras questões sociais e comerciais, através das instituições comuns: Parlamento Europeu, Conselho Europeu e Conselho da União Europeia. Dentro da UE, os Estados-membros continuam a ser nações soberanas e independentes, que debatem entre si as questões comuns ao grupo.

A interdependência dos Estados-membros e a atuação das instituições comuns têm garantido à UE um longo período sem guerras entre países, ainda que ocorram divergências de estratégias e propósitos. Apenas o Reino Unido aderiu à União Europeia sem aderir ao Euro, continuando com sua unidade monetária em Libras Esterlinas. Essa diferença pode ter sido um dos fatores relevantes para o brexit, ${ }^{2}$ devido ao peso de o país estar vincu-

2 Nome dado à saída do Reino Unido da União Europeia (2016). 
lado economicamente a um grupo sem sofrer os mesmos riscos e instabilidades que o restante. A falta de unidade nas questões referentes às políticas para refugiados, reformas trabalhistas e medidas de austeridade, aliada à assimetria econômica do bloco, também impactou na decisão. Isto aponta para a necessidade de que um bloco de integração tenha alinhados seus valores, apesar da soberania dos Estados.

A integração sul-americana tem, historicamente, propósitos econômicos e de criação de estruturas para facilitação comercial. Desde a criação da Associação Latino-Americana de Livre-Comércio (ALALC), em 1960, que em 1980 foi substituída pela Associação Latino-Americana de Integração (ALADI), o objetivo era criar, a longo prazo, um mercado comum na região, que, sem desfavorecer as relações bilaterais, pudesse impulsionar o desenvolvimento regional.

Paralelamente à ALADI, em 1991 foi fundado, por Brasil, Paraguai, Uruguai e Argentina, o Mercado Comum do Sul (MERCOSUL), projeto político e estratégico de integração no qual o aspecto comercial se soma a outras vertentes de igual ou maior importância (BRASIL, 2016). Além das questões comerciais, como a implementação de uma Tarifa Externa Comum (TEC), o MERCOSUL promove a livre circulação de pessoas, elabora programas para desenvolvimento social, promove os direitos humanos e financia a melhoria da infraestrutura regional.

Ainda sob os princípios da OEA, foi idealizada a UNASUL, que no seu Tratado Constitutivo estabelece propósitos amplos e ambiciosos de integração na América do Sul:

A União de Nações Sul-americanas tem como objetivo construir, de maneira participativa e consensuada, um espaço de integração e união no âmbito cultural, social, econômico e político entre seus povos, priorizando o diálogo político, as políticas sociais, a educação, a energia, a infraestrutura, o financiamento e o meio ambiente, entre outros, com vistas a eliminar a desigualdade socioeconômica, alcançar a inclusão social e a participação cidadã, fortalecer a democracia e reduzir as assimetrias no marco do fortalecimento da soberania e independência dos Estados. (UNIÃO DAS NAÇÕES SUL-AMERICANAS, 2008) 
A UNASUL foi uma iniciativa dos presidentes do Brasil, Lula da Silva, e da Venezuela, Hugo Chávez, que em 2008 estavam em ascensão política, com ideais de promoção social alinhados e com a pretensão de tornar o Subcontinente um grupo coeso e autônomo, livre da dependência dos Estados Unidos para planejamento e financiamento de seus setores estratégicos.

Chávez pretendia desenvolver integração em Defesa através da Aliança Bolivariana para os Povos de Nossa América (ALBA), associação com caráter bolivariano anti-imperialista criada como alternativa à Área de Livre Comércio das Américas (ALCA) para excluir os Estados Unidos da integração latino-americana. Porém, assim como a maioria dos países sul-americanos nos anos 2000, o Brasil também precisava de uma reestruturação do seu programa de Defesa. Em parceria com a Venezuela, propôs na UNASUL a criação do Conselho de Defesa Sul-americano, com o objetivo de integrar politicamente as estratégias de Defesa de cada país-membro em prol do objetivo comum de criar uma identidade sul-americana.

\section{O VALOR DOS RECURSOS NATURAIS SUL-AMERICANOS}

Entre tantos temas complexos que permeiam a relação entre países vizinhos, aquele relativo aos recursos naturais, sua defesa e preservação, bem como à exploração sustentável e ao aproveitamento responsável desses recursos, chama a atenção na América do Sul por sua necessidade de uso desses ativos essenciais. O Centro de Estudos Estratégicos de Defesa (CEED) é um órgão permanente do CDS que tem por missão contribuir para a consolidação de seus princípios e objetivos - entre eles, o de estruturar a América do Sul como uma zona de paz, transparência e confiança mútua, construindo uma identidade sul-americana. Em 2015, o CEED divulgou a primeira parte do Estudo Prospectivo América do Sul 2025, que faz uma projeção do desenvolvimento de um diagnóstico da realidade atual e das tendências para 2025 sobre o uso e a demanda dos recursos naturais estratégicos da região. De acordo com o documento: 
A América do Sul possui todos os recursos necessários para a subsistência humana, bem como todos os recursos necessários para a satisfação dos requisitos complexos e crescentes das estruturas tecnológico-produtivas das economias e sociedades atuais: a imensa riqueza do patrimônio natural da América do Sul varia entre as enormes e incomparáveis reservas de água doce, florestas, biodiversidade e capacidade de produção de alimentos para as diversas fontes de energia, reservas minerais gigantescas - quase monopolísticas, em mais de um caso - e as chamadas 'terras raras'. De acordo com as responsabilidades derivadas da proteção, defesa, preservação, exploração sustentável e uso endógeno dessa herança, é imperativo que nossos países coordenem estratégias e políticas funcionais para esses objetivos e interesses comuns; em outras palavras, é essencial alcançar, a nível regional, uma complementação e cooperação efetivas na implementação de cursos de ação concreta no assunto. (CENTRO DE ESTUDIOS ESTRATÉGICOS DE DEFENSA; CONSEJO DE DEFENSA SURAMERICANO; UNIÓN DE NACIONES SURAMERICANAS, 2015, tradução nossa).

A produção de alimentos no mundo depende essencialmente da disponibilidade de terras para cultivo agrícola e exploração pecuária, ainda levando em consideração a sustentabilidade ambiental e condições climáticas favoráveis. Na América do Sul, a extensão de áreas livres para plantio, de terreno fértil e clima ameno, proporciona o ambiente propício para o cultivo de grãos e cereais, além de espaço físico para criação de gado.

É possível afirmar que o território sul-americano é um ativo regional importante, com potencial para produzir alimentos para sua população na totalidade, e que na possibilidade de um novo conflito de alcance mundial a região estará sujeita a intervenções de outros países e de Organizações Internacionais para uso e exploração de suas terras.

Também a biodiversidade, que diz respeito à grande variedade de organismos e ecossistemas sobre um território específico, representa o capital natural de uma região, sendo tão importante quanto o capital econômico e o capital humano. Por esse motivo, 
assim como os países medem sua riqueza em termos econômicos, também devem considerar o ativo representado por sua biodiversidade.

A América do Sul é uma das regiões com maior biodiversidade do planeta, composta por 5 dos 17 países megadiversos do mundo: Brasil, Colômbia, Equador, Peru e Venezuela. O subcontinente possui mais de $40 \%$ das espécies de flora e fauna do mundo, em uma área menor que $15 \%$ da superfície mundial. (CEED; CDS; UNASUR, 2015)

O desmatamento para o uso do solo na expansão da agricultura comercial, visando atender a demanda internacional, é um dos maiores desafios na conservação desse habitat. Segundo a Organização das Nações Unidas (ONU), a área entre América Latina e Caribe corresponde a entre 50\% e 80\% de toda a biodiversidade do planeta. A comunidade científica internacional, os governos e as Organizações Não-Governamentais ambientalistas vêm advertindo o mundo para a perda de diversidade biológica, especialmente nas regiões tropicais. Alertam para a ameaça às espécies e ecossistemas devido ao impacto da atividade humana, que tem acelerado o processo de erosão e deterioração, ameaçando irreparavelmente as bases de desenvolvimento sustentável. A biodiversidade diminui na medida do crescimento demográfico e dos níveis de consumo, o que afeta a capacidade do mundo natural de continuar proporcionando os recursos dos quais depende a humanidade. Sua conservação é um dos mais sérios desafios globais.

A biodiversidade constitui uma das propriedades fundamentais da natureza, e é responsável pelo equilíbrio e estabilidade dos ecossistemas. Tem também um enorme potencial econômi$\mathrm{co}$, principalmente no que diz respeito à biotecnologia, que utiliza para fins produtivos o estudo e desenvolvimento de organismos biológicos.

A região amazônica é rica em biodiversidade, minérios e água doce, recursos naturais essenciais à vida e à economia. O fato de uma riqueza tão abundante ser compartilhada por nove países distintos, por si só, já explica a necessidade do desenvolvimento de políticas de Defesa em comum. A Amazônia compreende toda a região da bacia do rio Amazonas e grande área de floresta tropical, 
e ocupa um território de aproximadamente $7.800 .000 \mathrm{~km}^{2}$, distribuídos entre Brasil, Bolívia, Colômbia, Venezuela, Equador, Peru, Suriname, Guiana Francesa e Guiana. Além da necessidade de se estabelecer segurança nas fronteiras, a importância desse bioma demanda a criação de programas de uso sustentável pela sociedade local e legislação específica para a gestão da agricultura, pecuária, habitação e infraestrutura.

A água, mesmo sendo um elemento básico para a vida, é o recurso natural que possui menos estudos em termos de prospecção de sustentabilidade e reservas. A ONU publica anualmente um relatório sobre a água, o World Water Development Report. Seus mais recentes resultados têm sido alarmantes por mostrarem a rapidez com que esse recurso tão importante tem se tornado menos garantido. Em algumas comunidades mais ricas, como a União Europeia, a diminuição da oferta de água tem sido acompanhada por estudos de controle sobre o uso e o consumo, tanto para suprir necessidades vitais quanto para garantir a produção de bens.

A maior disponibilidade de reservas de água doce no planeta está nos aquíferos. Aquíferos são como reservatórios que se acumulam da água da chuva infiltrada no subsolo até encontrar uma camada impermeável. De fato, a água é um dos recursos mais abundantes do planeta: aproximadamente 70\% da esfera terrestre são cobertos de água. No entanto, apenas uma pequena parte é adequada para consumo humano, e os aquíferos representam 30,1\% dessa porção.

De acordo com o Programa da Organização das Nações Unidas para a Educação, a Ciência e a Cultura (UNESCO), a soma da área de todos os aquíferos detectados nas Américas alcança, aproximadamente, $8.000 .000 \mathrm{~km}^{2}$.

$\mathrm{Na}$ América do Sul, dos pelo menos 30 aquíferos transfronteriços conhecidos, o Sistema Aquífero Guarani (SAG) é o maior deles. O corpo hídrico subterrâneo, que abrange parte dos territórios da Argentina, do Brasil, do Paraguai e do Uruguai, possui um volume acumulado de $37.000 \mathrm{~km}^{3}$, de acordo com o Projeto de Proteção Ambiental e Desenvolvimento Sustentável do Ministério do Meio Ambiente brasileiro. É o segundo maior aquífero do mundo, 
ficando atrás apenas do Sistema Aquífero Grande Amazônia, no Brasil, e que não é compartilhado com outros países.

As perspectivas de crescimento da demanda mundial de água são maiores nos países que atualmente experimentam maior dinamismo, tanto no crescimento econômico como no crescimento populacional. Nos países da UNASUL, o crescimento populacional implica um aumento de demanda nos próximos anos, tanto pelo consumo da população quanto para produção. O aumento da demanda de biocombustíveis e da área de produção agrícola, a partir do desenvolvimento tecnológico, também terá um peso significativo no futuro do consumo de água na região. Somamse a isto os programas que promovem maior alcance da oferta de água potável nas grandes cidades, impactando diretamente no volume utilizado.

Amazônia Azul é o termo utilizado pelo Ministério da Defesa brasileiro para designar seu território marítimo, equivalente à Amazônia em área, recursos naturais, biodiversidade e necessidade de proteção ambiental. Com cerca de aproximadamente 3,6 milhões de $\mathrm{km}^{2}$, pelo território marítimo brasileiro passam 95\% do comércio exterior nacional, movimentando os mais de 40 portos em toda a região costeira (BRASIL, 2015). Diante da insuficiência de apenas um setor da Defesa brasileira para a proteção de uma área tão grande, o Ministério da Defesa brasileiro desenvolve, em conjunto com a ONU, programas específicos para a definição do Direito do Mar. De acordo com a determinação da Convenção das Nações Unidas sobre os Direitos do Mar (CNUDM), de 1982, na chamada Zona Contígua e na Zona Econômica Exclusiva (ZEE) o estado costeiro não pode, por exemplo, negar o chamado "direito de passagem inocente" a navios de outras bandeiras, inclusive navios de guerra. ${ }^{3}$ Essa determinação, alvo de propostas brasileiras para revisão na CNUDM, representa um risco para todo o Subcontinente, principalmente Uruguai, Paraguai e Argentina, mais próximos da costa sul do Brasil.

3 A Zona Contígua compreende uma área com mais 12 milhas de largura, a contar do limite externo do mar territorial. A Zona Econômica Exclusiva, com 200 milhas de largura, engloba o mar territorial e a Zona Contígua. 
O petróleo, o carvão e o gás natural são os recursos energéticos mais utilizados no mundo, constituindo fonte essencial de energia. A região sul-americana é possuidora de grande parte desses recursos, com 19,7\% das reservas mundiais de petróleo bruto. Apesar disso, a região não chega a consumir o que produz. Possui, portanto, capacidade suficiente para subsistência autônoma (CEED; CDS; UNASUR, 2015).

O Estudo Prospectivo Suramérica 2025, do CEED-CDS, menciona as estatísticas do US Energy Information Administration, que apontam a Ásia e a Oceania como os maiores consumidores de petróleo em 2013, com 33\% do consumo mundial. Isso demonstra que a distribuição desigual desse recurso natural torna ainda mais importante a proteção e a boa gestão dos mesmos.

Na última década, o Brasil se tornou uma referência em matéria de estratégia energética com a descoberta de petróleo na camada pré-sal no litoral sudeste. Segundo os relatórios da Petrobras, esta reserva atingiu, em 2016, a marca de 1 milhão de barris por dia. Somando com a Venezuela, fica claro por que a América do Sul voltou a ser alvo da intervenção direta e indireta dos Estados Unidos, fato que será abordado com maior profundidade a seguir.

\section{O CDS COMO INSTRUMENTO DE COOPERAÇÃO NA AMÉRICA DO SUL}

A ausência de um ambiente de diálogo sistemático e estruturado sobre as questões de Segurança e Defesa na América do Sul faz com que seus países estejam inseridos no sistema internacional com menos força política do que realmente possuem. Por não haver articulação conjunta para o desenvolvimento, toda a região fica sujeita às intervenções externas - principalmente dos Estados Unidos, que sempre atuaram na América do Sul com liberdade, envolvendo-se nas questões internas como Estado "mediador" sempre que foi de seu interesse. Na vigência do CDS, todas as controvérsias entre países membros serão intermediadas por um grupo de países irmãos, que têm objetivos em comum e prezam pelo respeito à soberania e autodeterminação dos povos. 
Essa autonomia traz para a América do Sul a possibilidade de desenhar uma estratégia de Defesa única, onde haja equilíbrio das assimetrias e cooperação para o desenvolvimento.

No ano de 2011, o então Ministro da Defesa, Celso Amorim, ilustrou a estratégia do Conselho de Defesa Sul-americano como "cooperação para dentro, e dissuasão para fora", exemplificando o propósito de sua criação. O papel principal do Conselho é estabelecer na América do Sul uma zona pacífica, porém forte e preparada. "Um Estado neutro depende, por definição, da dissuasão: não pretende impor aos demais sua própria vontade, a não ser se para convencê-los a não interferir com sua independência" (ARON, 2002, p. 509). A exemplo disso, o CDS foi proposto na UNASUL no momento em que uma incursão do exército colombiano em território do Equador, em um acampamento das FARC, fez levantar a necessidade de diálogo para definição de diretrizes comuns no campo da Defesa regional.

Em seu Estatuto, o Conselho de Defesa Sul-Americano se apresenta como "instância de consulta, cooperação e coordenação em matéria de Defesa em harmonia com as disposições do Tratado Constitutivo da UNASUL" (UNIÃO DAS NAÇÕES SUL AMERICANAS, 2008), e tem como objetivos gerais:

a) consolidar a América do Sul como uma zona de paz, base para a estabilidade democrática e o desenvolvimento integral de nossos povos, e como contribuição para a paz mundial.

b) construir uma identidade sul-americana em matéria de defesa, que leve em conta as características sub-regionais e nacionais e que contribua para o fortalecimento da unidade da América Latina e o Caribe.

c) gerar consensos para fortalecer a cooperação regional em matéria de Defesa.

Dentre os objetivos específicos do CDS, destacam-se: o compartilhamento de uma visão única a respeito das tarefas referentes à defesa, o intercâmbio no âmbito da indústria de defesa e formação militar e a troca de experiências a respeito dos processos de modernização dos Ministérios da Defesa e das Forças Armadas. 
A produção de uma visão compartilhada de defesa é a ação base para que sejam alcançados os outros objetivos, pois é o ponto de partida para a definição das doutrinas de Segurança e Defesa que vão nortear o treinamento de militares e possibilitar a confiança mútua para a troca de tecnologia bélica a que se propõe o Conselho.

No caso dos recursos naturais sul-americanos, é necessário que a estratégia de Defesa dos recursos transfronteriços seja comum aos países da região para que haja coesão nas políticas adotadas e para que nenhum país coloque em risco o bem comum para atender suas próprias demandas domésticas, como no caso do alinhamento militar da Colômbia com os EUA. Além disso, é necessário incutir no pensamento macro de outros países a necessidade de proteção desses recursos, já que nem todos fazem referência aos recursos naturais como sendo ponto estratégico para Defesa - por exemplo, Bolívia, Colômbia e Uruguai (PENNAFORTE, 2012).

Para viabilizar o intercâmbio da formação militar regional, em 2015 entrou em atividade a Escola de Defesa Sul-americana (ESUDE). Segundo seu Secretário Geral, Antônio Jorge Ramalho:

O compartilhamento de recursos humanos e didáticos favorecerá o diálogo franco entre civis e militares, permitindo-lhes identificar interesses comuns na agenda de segurança internacional e consolidar o alto nivel de transparência na gestão de seus sistemas de defesa. (RAMALHO, 2015).

É muito delicada a questão do treinamento conjunto de exércitos, considerando que a ação militar é motivada pelo propósito de construção ou proteção da nação, conforme descreve Domingos Neto:

A guerra tem se revelado o mais poderoso fator de identificação de comunidades; no tempo moderno, fornece a matéria-prima para a elaboração emocional do passado, requerida nos processos de identificação coletiva, anima a economia e a produção de conhecimento (DOMINGOS NETO, 2005, p. 46). 
Isto posto, se não houver identificação coletiva com o propósito da guerra, ou, nesse caso, da preparação para a mesma, não haverá coesão entre as ações, motivação na coletividade ou empenho em defender o que não é, diretamente, interesse próprio do Estado nacional.

Os países sul-americanos tiveram sua história formada por anos de colonização europeia, através da qual foram explorados em seus recursos naturais e humanos sem nenhum projeto inicial de desenvolvimento de Estado ou investimento em infraestrutura. À medida que se tornaram independentes, cada país teve que construir seu próprio desenvolvimento, já em atraso em comparação com o restante do mundo, sem capacidade de ser economicamente independente, e principalmente sem autonomia de Defesa.

Já no período em que Espanha, Portugal, Holanda e Inglaterra tinham o domínio da América Latina, os Estados Unidos procuravam demonstrar sua força e influência sobre o território americano. Uma vez que a maioria dos países se tornou independente, a projeção dos EUA sobre a América Latina foi natural. Além dos recursos naturais descritos anteriormente, o mercado latino-americano, carente de produtos manufaturados, também atrai o interesse estadunidense. Outro fator determinante neste cenário é o interesse da grande potência em preservar sua hegemonia através de ações somadas, que vão desde infundir seus valores através de movimentos culturais e propaganda subliminar até intervenções armadas disfarçadas de apoio à democracia (COSTA, 2007).

Desde a aplicação da Doutrina Monroe, em 1823, os Estados Unidos vêm redesenhando sua política externa para a América Latina de maneira a tornar a região dependente de seu controle. ${ }^{4}$ Seja por ideais expansionistas ou para garantir um futuro de exploração, os Estados Unidos têm se posicionado como líder regional, exercendo influência sobre todos os países da América Latina e Caribe no período pós-independência. Sob o pretexto de impedir a intervenção europeia, de coibir o comunismo, e depois

4 Doutrina do Presidente americano James Monroe para a América Latina, contra a influência europeia na região, consolidando a mensagem de "América para os americanos". 
de "garantir o exercício da democracia", os EUA impõem sua presença militar no continente sul-americano firmando parcerias com Chile, Colômbia, Argentina e Brasil, em acordos bilaterais de cooperação, que, de forma assimétrica, permitem-lhe manter a vigilância na região sem que os países latino-americanos tenham acesso à tecnologia de ponta e a informações relevantes na esfera da Segurança e Defesa dos EUA. Durante o período da Guerra Fria (1945 - 1989), os EUA dedicaram grande parte de sua força militar ao combate ao comunismo; no esforço para evitar a influência soviética na América Latina e no Caribe, financiaram os governos militares instaurados no Brasil, na Argentina, no Chile, no Peru, no Paraguai e no Uruguai (BANDEIRA, 2003).

Indiretamente, também o Fundo Monetário Internacional (FMI) e o Banco Internacional de Desenvolvimento (BID) operam nos países latino-americanos: impõem medidas de austeridade que desaceleram o crescimento e geram laços de dependência com a potência econômica, que por sua vez adquire a prerrogativa de definir políticas econômicas e influenciar decisões estratégicas locais.

Um dos principais problemas de Segurança Internacional na América do Sul é causado pelo narcotráfico, principalmente na Colômbia e no Paraguai. No caso da Colômbia, o narcotráfico tem consequências políticas graves, uma vez que seu lucro ajudou a fortalecer o grupo guerrilheiro Forças Armadas Revolucionárias da Colômbia (FARC), fazendo com que a instabilidade gerada no país represente o foco de sua estratégia de Defesa. Essa necessidade fez com que o país firmasse acordos de cooperação militar com os EUA, que hoje já possuem sete bases militares na Colômbia, mesmo após o Acordo de Paz firmado em 2016 com as FARC. A motivação da caríssima manutenção dessas bases em território sul-americano não é clara e tem causado tensão com a Venezuela e o Equador. (ABDUL-HAK, 2013).

Outro exemplo de atuação militar estadunidense na América Latina foi em 2008, com a reativação da IV frota. Trata-se de uma esquadra da Marinha Americana posicionada no Atlântico Sul, próxima ao litoral brasileiro, sem acontecimento que justifique sua presença, exatamente no auge da exploração petrolífera do pré-sal. 
O risco de a América do Sul perder autonomia em Defesa não diz respeito apenas à influência do EUA na região. Também a China tem demonstrado forte interesse em nossos recursos. No início de 2017, o grupo estatal chinês State Grid fechou um acordo para comprar 54,64\% da gigante brasileira de eletricidade CPFL Energia por 14,19 bilhões de reais, mesmo sendo a distribuição de energia um setor estratégico nacional - tão estratégico que a tentativa de compra da rede elétrica australiana, no ano anterior, fora negada por motivos de segurança nacional (CHINESA..., 2017).

Internamente, pesam as relações entre países vizinhos, como Colômbia e Venezuela, afetados pelo apoio militar estadunidense à Colômbia. A Venezuela tem sido alvo de sanções da parte dos EUA, cuja justificativa seria a defesa da população contra o regime não democrático de Nicolas Maduro. Além de afetar significativamente a economia venezuelana, a influência estadunidense provoca um efeito social desestabilizador disseminado, sobretudo, por grupos de oposição financiados por investimento estrangeiro em ONGs e milícias organizadas.

A relação entre Peru e Equador também não é amistosa, o que pode impactar os assuntos de Defesa em algum momento. A competição pela liderança regional entre Brasil e Argentina gera sempre tensão nas relações diplomáticas entre os dois países. Embora tenham estabelecido acordos na área de Defesa, suas dimensões territoriais e grandeza econômica fazem com que os eventuais impasses em decisões comuns à região tenham reflexo para fora do subcontinente.

\section{CONSIDERAÇÕES FINAIS}

O dissenso regional para questões estratégicas afeta não só a Defesa regional como também os países individualmente, em suas políticas nacionais de Defesa.

Não obstante, os países seguem se relacionando continuamente, compartilhando território, negociando estruturas comerciais e criando políticas próprias, cada um a partir de sua perspectiva ideológica de Nação. Portanto, mecanismos que facilitem a 
comunicação entre os Estados e as Organizações Internacionais são essenciais para o bom funcionamento da dinâmica internacional.

A América do Sul, mesmo sendo majoritariamente pacífica, é uma região onde a manutenção da paz carece de atualizações constantes dos termos de troca, relações de confiança e equilíbrio de poder. Todos os países sul-americanos declaram uma política interna pacífica para o continente. Entre manter um ambiente livre de conflito e de fato agir na cooperação, porém, existe um abismo de desafios a serem superados.

Visto que os Estados necessitam de proteção na assimetria do Sistema Internacional, aqueles que não conseguem garantir sozinhos a defesa de suas soberanias (como é o caso dos países sul-americanos) procuram se alinhar a uma potência militar próxima, mesmo que isso signifique abdicar de parte de sua autonomia. Esta não deve ser, necessariamente, a única estratégia para Defesa. O objetivo do CDS de criar uma identidade de Defesa Sul-americana propõe um projeto inovador, onde Estados se unem para contrabalancear o sistema atual. A ideia de que o conjunto de países "em desenvolvimento" pode funcionar como um "bloco militar" confere à região a perspectiva de alcançar o mesmo nível de dissuasão das grandes potências.

Muito promissor na teoria, o CDS enfrenta desafios complexos para atuar na prática. O primeiro deles é a alteração da inclinação ideológica dos governos na América do Sul, que no momento da idealização do Conselho viviam o auge da onda progressista de esquerda, encabeçada por Chávez e Lula. Movida pela tendência anti-imperialista dos governos do Brasil, da Venezuela, da Bolívia e da Argentina, a UNASUL e seus mecanismos caminhavam para uma nova era da integração sul-americana. Hoje, Brasil e Argentina, as maiores economias sul-americanas, são liderados sob paradigmas neoliberais americanistas; a UNASUL, e com ela o CDS, torna-se apenas mais um Tratado irrelevante no cotidiano das questões regionais. A prova disso é que ambos os países hoje têm desenvolvido exercícios militares com os EUA, ao mesmo tempo em que abandonaram os estudos estratégicos entre si (o mais recente é de 2015). 
Enquanto esfriam as relações de confiança construídas dentro da UNASUL, as ameaças estrangeiras continuam se tornando um risco real e mais espaço ganham as grandes potências na exploração dos recursos regionais.

Mesmo os Estados que não pretendem se alinhar aos EUA têm procurado em outros grupos a alternativa de Defesa que o CDS não está proporcionando, como o aprimoramento da Escola de Defesa da ALBA, ou o espaço de diálogo proporcionado pela Comunidade de Estados Latino-Americanos e Caribenhos (CELAC), que funciona como foro paliativo, sem intenção de desenvolver uma unidade comum em Defesa. Com isso, perde-se o potencial de desenvolver uma identidade autônoma na região. O interesse em desenvolver a indústria, os treinamentos e as doutrinas das Forças Armadas são comuns aos países da América do Sul, mas a necessidade de consenso nas decisões exige um longo processo de integração além do âmbito comercial.

Longe de esgotar o tema, concluo expondo a necessidade do imediato estabelecimento de uma força regional de Defesa comum para a proteção dos Recursos Naturais da América do Sul. Ainda que o CDS demande ajustes em sua proposta, ele apresenta base suficiente para uma pesquisa mais aprofundada, inclusive no que tange às questões não tratadas aqui, como a Defesa contra o terrorismo, o narcotráfico e o estabelecimento de uma Indústria Comum de Defesa - aspectos também abordados pela UNASUL em seu Tratado Constitutivo.

\section{REFERÊNCIAS}

ABDUL-HAK, A. P. N. O Conselho de Defesa Sul-Americano / CDS: objetivos e interesses do Brasil. Brasília: FUNAG, 2013.

ARON, R. Paz e guerra entre as nações. Tradução de Sérgio Bath. São Paulo: Ed. UNB, 2002. (Coleção Clássicos IPRI). Disponível em < http:// funag.gov.br/loja/download/43-Paz_e_Guerra_entre_as_Nacoes.pdf>. Acesso em 24 nov. 2018.

BATTAGLINO, J. O Brasil e a criação do Conselho de Defesa Sul-Americano: uma convergência de vantagens. Tradução de Ivony Lessa. Revista 
Nueva Sociedad, p.79-89, 2009. Disponível em: <http://nuso.org/media/ articles/downloads/p7-6_1.pdf > Acesso em: 19 nov. 2016.

BRASIL. Ministério da Defesa. Normativa UNASUL-CDS-CEED-ESUDE. 2017. Disponível em: <https://www.defesa.gov.br/arquivos/relacoes_ internacionais/unasul/normativa_unasul_2017.pdf >. Acesso em 19 nov. 2018.

Ministério da Defesa. Marinha do Brasil. Amazônia Azul. 2015. Disponível em: <https://www.marinha.mil.br/amazonia-azul>. Acesso em: 19 nov. 2018.

Ministério das Relações Exteriores. Mercosul. 2016. Disponível em: <http://www.itamaraty.gov.br/pt-BR/politica-externa/integracaoregional/686-mercosul>. Acesso em 02 nov. 2017.

Ministério das Relações Exteriores. Associação LatinoAmericana de Integração (ALADI). 2014. Disponível em: <http:// www.itamaraty.gov.br/pt-BR/politica-externa/integracao-regional/690associacao-latino-americana-de-integracao-aladi>. Acesso em 02 nov. 2017.

BRASIL. Ministério do Meio Ambiente. Aquífero Guarani. [2012?]. Disponível em: <http://www.mma.gov.br/informma/item/8617-aquiferoguarani>. Acesso em: 15 ago. 2017.

CARR, E. Vinte anos de Crise 1919-1939. 2.ed. Brasília: Editora Universidade de Brasília, 2001.

COSTA, C A. da. O Afeganistão na propaganda de guerra dos Estados Unidos da América. 2007. 112 f. Trabalho de Conclusão de Curso (Graduação em Comunicação Social) - Universidade Federal do Ceará, Fortaleza, 2007.

CENTRO DE ESTUDIOS ESTRATÉGICOS DE DEFENSA; CONSEJO DE DEFENSA SURAMERICANO; UNIÓN DE NACIONES SURAMERICANAS. Estudio prospectivo Suramérica 2025: primera parte. Buenos Aires, 2015. Disponível em: <http://ceed.unasursg.org/Espanol/09Downloads/ Biblioteca/RRNN2025.pdf> Acesso em: 02 ago. 2017.

CHINESA State Grid compra brasileira CPFL Energia por US\$ 4,5 bilhões. O Estado de Minas, Belo Horizonte, 24 jan. 2017. Caderno Internacional. Disponível em: <https://www.em.com.br/app/noticia/ internacional/2017/01/24/interna_internacional,842033/chinesa-stategrid-compra-brasileira-cpfl-energia-por-us-4-5-bilhoes.shtml >. Acesso em 18 nov. 2018. 
DOMINGOS NETO, M. Políticas de defesa e segurança para o Atlântico Sul no século XX. Tensões Mundiais, Fortaleza,v. 12, n. 22, p. 17-32, 2016.

O militar e a civilização. Tensões Mundiais, Fortaleza, v.12, n.1, p. 37-70, 2005.

GUIMARÃES, S.P. O mundo multipolar e a integração Sul-Americana. Revista Temas \& Matizes, n. 14, p. 58-72, 2008. Disponível em: $<$ http://e-revista.unioeste.br/index.php/temasematizes/article/ view/2484>. Acesso em: 07 nov. 2017.

MONIZ BANDEIRA, L. A. Brasil, Argentina e Estados Unidos: Conflito e Integração na América do Sul -Da Tríplice Aliança ao Mercosul. Rio de Janeiro: Revan, 2003.

A. A importância geopolítica da América do Sul na estratégia dos Estados Unidos. Revista da Escola Superior de Guerra, Rio de Janeiro, v. 24 , n. 50, p. 7-35, jul./dez.2008.

NAFALSKI, G. P. N. Unasul: uma perspectiva política de integração sul-americana. 2010. 109f. Dissertação (Mestrado em Sociologia) Universidade de São Paulo, São Paulo, 2010.

NOGUEIRA, J. P.; MESSARI, N. Teoria das Relações Internacionais: correntes e debates. 19. ed. Rio de Janeiro: Elsevier, 2005.

PENNAFORTE, C. A Defesa Nacional frente ao dilema da integração sulamericana. In: PIERI, V. S. G. de et al. (Org.). Defesa Nacional: desafios e perspectivas geopolíticas. Rio de Janeiro: CENEGRI, 2012. cap. 1, p. 18-30.

RAMALHO, A. J. A Escola de Defesa Sul-Americana, por Antonio Jorge Ramalho. Revista Mundorama, 2015. Disponível em: <https://www. mundorama.net/?p=16275>. Acesso em 03 nov. 2018.

REZENDE, L. P. Sobe e desce: explicando a Cooperação em Defesa na América do Sul. Brasília: Ed. UNB, 2015.

ROUSSEAU, J.J. O contrato social. São Paulo: Russel, 2006.

SANTOS, L. C. V. G. A América do Sul no discurso diplomático brasileiro. Brasília: FUNAG, 2014.

SCOLARI, D. D. G. Produção agrícola mundial: o potencial do Brasil. 2006. Disponível em: <http://www.alice.cnptia.embrapa.br/alice/handle/ doc/417182>. Acesso em: 02 nov. 2017. 
SENRA, R. Exército dos EUA participará de exercício militar inédito na Amazônia a convite do Brasil. BBC Brasil, Washington, 7 maio 2017. Disponível em: <http://www.bbc.com/portuguese/brasil-39802863>. Acesso em: 03 nov. 2017.

UNIÃO DAS NAÇÕES SUL-AMERICANAS. Tratado Constitutivo da União de Nações Sul-Americanas (UNASUR). Brasília, 2008. Disponível em: $<$ http://www.itamaraty.gov.br/images/ed_integracao/docs_UNASUL/ TRAT_CONST_PORT.pdf > Acesso em: 02 nov. 2016. 